\title{
Editorial
}

\section{COVID-19 Outbreak: The North versus South Epidemiologic Italian Paradigm}

Since COVID-19 outbreak has spread from Wuhan (China) to worldwide, many Countries are dealing with the impact of this pandemic on different aspects of their lives: sanitary, sociocultural and economic. Italy represents a paradigm of different effects of pandemic on citizens' health. In fact, North Italy showed high rates of transmission [mean national transmission index $\left(R_{t}\right)$ referred to the February-April 2020 period was always $>1$ in North Italy regions, while $<1$ in South Italy)] and mortality (5.4\% of positive cases in Lombardia -North Italy- vs $1.3 \%$ in Campania -South Italy-) due to severe pneumonitis while South Italy displayed a very low epidemic curve suggesting that contagiousness and/or virulence could be lower than North Italy [1-4]. Furthermore, both in the first phase of COVID-19-related crisis (February-April 2020) and in the second one started in September 2020 the COVID-19-specific death ratio North:South was 5:1 with a standardized mortality ratio from 3 to 7.5 in North versus 0.012 to 0.5 in South Italy [1-4].

None of the factors suggested initially accounted for the significant difference between North and South Italy. Some comorbidities such as diabetes, hypertension and Chronic Obstructive Pulmonary Disease have the same prevalence in North and South Italy [5-8] even if diabetes is more common in the regions of South. Overall smoking rates are similar across Italy, however, some gender differences are observed such as higher rates of smoking women in the north. However, most of the dead in North Italy are males suggesting that biological and/or immunological gender-related factors might be involved in determining pneumonitis severity. Conversely, there is a significant prevalence of overweight and obese people in South Italy, across all age groups. The last data should eventually promote the negative impact of the virus on health of South Italy people. Furthermore, aged people ( $>65$ years old), where most of dead are concentrated, are also equally distributed in Italy considering the absolute numbers and regions' surface [2-4]. Contacts with Chinese entrepreneurship are also neither a discriminating nor a detrimental factor since relationships were intense in both North and South Italy.

Very recently, some Italian researchers [9] indicated pollution as a possible major determinant of both contagiousness and severity of COVID-19 in North Italy. In fact, a large part of North Italy is constituted by a flat land called "Pianura Padana" where there are concentrated the most important industries and cities of Italy. High pollutants concentration and microclimatic condition (wet and cold air, fog formation, scarce wind remodeling) favors the wellknown phenomenon of "thermal inversion": a large mass of cold air in contact with the ground is trapped under a layer of warmer air. The density of these masses is so different that mixing is impossible in absence of significant rain or wind.

Unfortunately, the pollutants trap, concentrate and concur to increase the density of the inferior layer [10-12]. This vicious circle produces a "pollution beret", visible from the space through satellite normal photos as well as through technical assessment of specific gasses' concentration (whose explanation is beyond the scope of this letter) (Figure 1).

Most of air pollutants (i.e., carbon monoxide, sulfur dioxide, nitrogen dioxide, ozone, polycyclic aromatic hydrocarbons, creosote, particulate, etc.) interact to form stable complex macromolecular "rafts". These "rafts" participating to the composition of Particulate Matter (PM) have been frequently associated with virus-related syndromes $[13,14]$. In fact, viruses can interact with these particles and be contagious at unexpected distances $[15,16]$. It has also been demonstrated a profound difference in North and South Italy for the microplastic waste distribution. In fact, a recent study demonstrated that the accumulation of microplastics among driftlines showed no consistent pattern, besides expanded polystyrene tending to accumulate backshore of the Po River Delta in northeast Italy. The accumulation hotspots within a single driftline can disrupt a general observed accumulation pattern [17]. In support of this model, a survey is presented in Table 1.

COVID-19 is an enveloped and single-stranded ribonucleic acid virus with 9-12 nm-long spikes surrounding the surface and conferring it the form of a solar corona at electron microscope [18]. Spike glycol-protein S binds to Angiotensin-converting Enzyme 2 (ACE2) receptor on host cells triggering the subsequent fusion between the viral envelope and cellular membrane. ACE2, mainly expressed on lungs, vasculature and intestine, is an enzyme of the Renin-Angiotensin System [19,20]. The main enzymatic pathway involved in the catabolism of angiotensin peptides can be briefly summarized as follows: renin, secreted by juxtaglomerular kidney cells, cleaves angiotensinogen in angiotensin I (decapeptide with no direct biological activity), which is, in turn, cleaved by ACE in angiotensin II (Ang II) (which induces vasoconstriction). ACE2 converts Ang II to Ang-(1-7) a vasodilator, thus counteracting the activity of ACE. Interestingly, chronic inflammation is associated to increased expression of ACE2 [21] and impairments of T lymphocytes functions [22-24]. As already explained, ACE2 is a critical factor for virus pathogenesis. Thus, pollutants and microclimate may concur (1) to favor virus "transport" into lungs and (2) to 


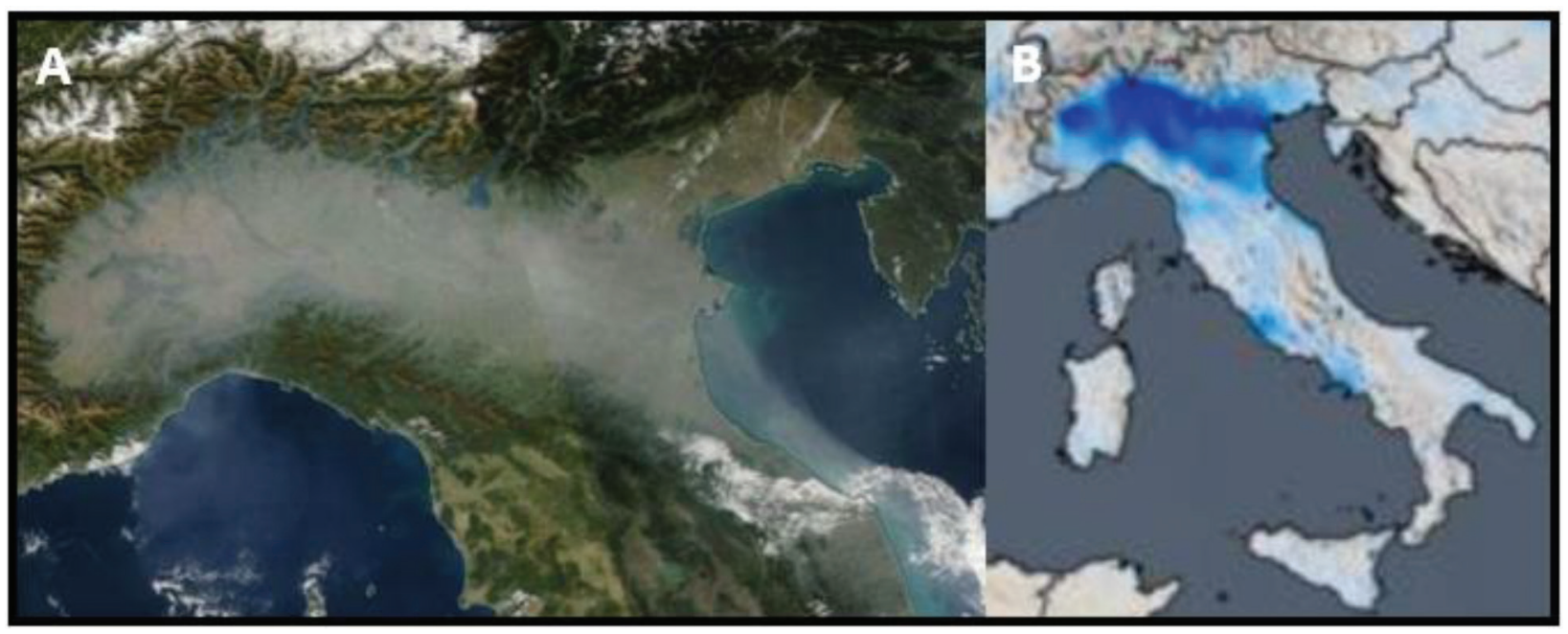

Figure 1 (A) Photo showing the smog on Pianura Padana. (B) Intensity and distribution of nitrogen dioxide tropospheric column (blue color) (images from National Press).

Table 1 Evidence supporting a direct role of air particles in transporting viruses

\begin{tabular}{|c|c|c|c|c|c|c|c|c|c|}
\hline Year & Author & Journal & $\begin{array}{l}\text { Experimental } \\
\text { model }\end{array}$ & $\begin{array}{l}\text { Method } \\
\text { for virus } \\
\text { detection }\end{array}$ & $\begin{array}{l}\text { Air-sample } \\
\text { collection } \\
\text { time period }\end{array}$ & Primary end-point & Virus & Family & Diameter (nm) \\
\hline 2009 & Dee S & Vet Res & Pigs & RT-PCR & 50 days & IAPS: Until to $4700 \mathrm{mt}$ & PRRSV & Arteriviridae & $45-70$ \\
\hline 2010 & Otake S & Vet Micorbiol & Pigs & RT-PCR & 21 days & IAPS: Until to $9100 \mathrm{mt}$ & PRRSV & Arteriviridae & $45-70$ \\
\hline 2014 & Alonso C & Vet Res & Pigs & RT-PCR & $63 \mathrm{~h}$ & IAPS: Until to 10 miles & PEDV & Coronaviridae & $90-190$ \\
\hline \multirow[t]{4}{*}{2015} & Alonso C & PLoS One & Pigs & RT-PCR & 13 days & $\begin{array}{l}\text { DIPS: Continuous } \\
\text { increase of infectivity } \\
\left(\text { copies } / \mathrm{mm}^{3} \text { ) with }\right. \\
\text { particle size. } \\
\text { Particle size from } \\
0.4 \text { to }>9 \mu \mathrm{m} \text {. }\end{array}$ & & & \\
\hline & & & & & & IAV: $8 \times 10^{2}$ to $4.3 \times 10^{5}$ & IAV & Orthomyxoviridae & $80-120$ \\
\hline & & & & & & $\begin{array}{l}\text { PEDV: } 1.3 \times 10^{6} \text { to } \\
3.5 \times 10^{8}\end{array}$ & PEDV & Coronaviridae & $90-190$ \\
\hline & & & & & & $\begin{array}{l}\text { PRRSV: } 6 \times 10^{2} \text { to } \\
5.1 \times 10^{4} . \\
\text { Higher numbers of } \\
\text { RNA copies were } \\
\text { associated with } \\
\text { larger particles. }\end{array}$ & PRRSV & Arteriviridae & $45-70$ \\
\hline \multirow[t]{6}{*}{2017} & Alonso C & $\begin{array}{l}\text { J Vet Diagn } \\
\text { Invest }\end{array}$ & $\begin{array}{l}\text { Pigs and } \\
\text { chickens }\end{array}$ & RT-PCR & 11 days & $\begin{array}{l}\text { DIPS: Continuous } \\
\text { increase of infectivity } \\
\left(\text { copies } / \mathrm{mm}^{3}\right) \text { with } \\
\text { particle size. }\end{array}$ & & & \\
\hline & & & & & & $\begin{array}{l}\text { Particle size from } \\
\quad<1 \text { to }>3 \mu \mathrm{m} .\end{array}$ & & & \\
\hline & & & & & & $\begin{array}{l}\text { HPAIV: from } \\
4 \text { to } 5 \text { Log. }\end{array}$ & HPAIV & Orthomyxoviridae & $80-120$ \\
\hline & & & & & & $\begin{array}{l}\text { PEDV: from } \\
5 \text { to } 6 \text { Log. }\end{array}$ & PEDV & Coronaviridae & $90-190$ \\
\hline & & & & & & $\begin{array}{l}\text { PPRSV: from } \\
2 \text { to } 5 \text { Log. }\end{array}$ & PRRSV & Arteriviridae & $45-70$ \\
\hline & & & & & & $\begin{array}{l}\text { Higher numbers of } \\
\text { RNA copies were } \\
\text { associated with } \\
\text { larger particles. }\end{array}$ & & & \\
\hline
\end{tabular}

DIPS, distribution and infectivity by particle size (distance); IAPS, infectivity of airbone particles from the source (number of virus copies/mm³); HPAIV, highly pathogenic avian influenza virus; IAV, influenza A virus; $\mathrm{mt}$, meters; PEDV, porcine epidemic diarrhea virus; PRRSV, porcine reproductive and respiratory syndrome virus; RT-PCR, reverse transcriptase-polymerase chain reaction. 


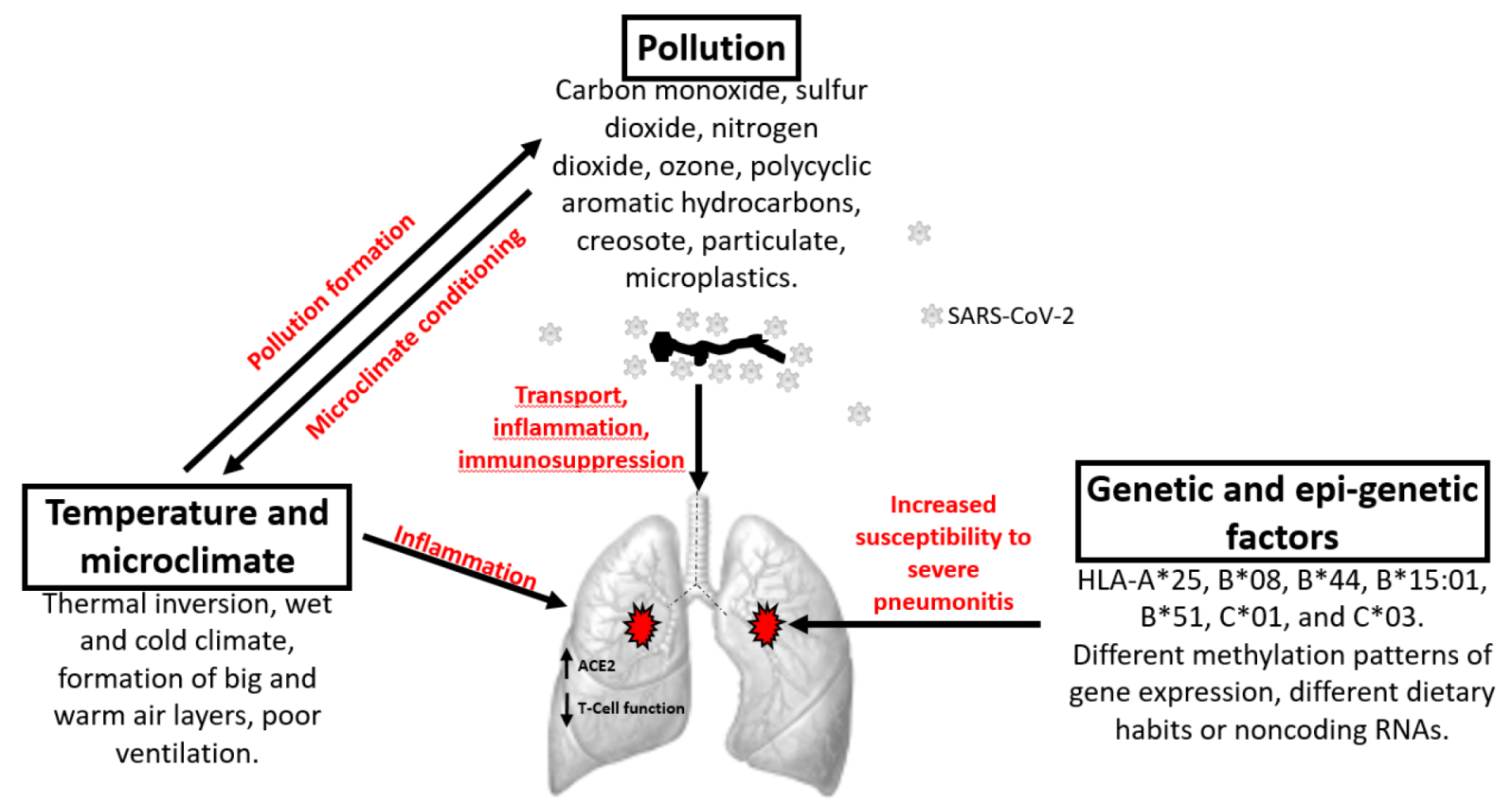

Figure 2 Factors concurring on favoring COVID-19 infection in North Italy.

promote cells' infection by increasing the inflammatory status of lungs (and thus increasing ACE2 expression) and producing an immune depressive contexture (Figure 2).

Beside the environmental reasons of the different severity of the syndromes associated to COVID-19 infection, genetic determinants can contribute to this different clinical outcome. In fact, it has been recently described a strong correlation among the interstitial pneumonitis induced by the treatment with Immunological Checkpoint Inhibitors (ICIs) in cancer patients (highly resembling the COVID-19-induced pneumonitis) and germinal expression of HLA-B $* 35$ and DRB1 $* 11$ alleles associated to autoimmune diseases [25]. The expression of some HLA alleles was also correlated to the response to ICIs [26]. Moreover, a set of HLA alleles (A, B, C), known to be involved in the immune response against infections, correlates with COVID-19 incidence in Italy. COVID-19 data were provided by the National Civil Protection Department, whereas HLA allele prevalence was retrieved through the Italian BoneMarrow Donors Registry. Among all the alleles, HLA-A*25, B*08, $\mathrm{B} * 44, \mathrm{~B} * 15: 01, \mathrm{~B} * 51, \mathrm{C} * 01$, and $\mathrm{C} * 03$ showed a positive log-linear correlation with COVID-19 incidence rate fixed on 9 April 2020 in proximity of the national outbreak peak (Pearson's coefficients between 0.50 and $0.70, p<0.0001$ ), whereas HLA-B $* 14, \mathrm{~B} * 18$, and $\mathrm{B} * 49$ showed an inverse log-linear correlation. When the alleles were examined simultaneously using a multiple regression model to control for confounding factors, HLA-B $* 44$ and $\mathrm{C} * 01$ were still positively and independently associated with COVID-19. Interestingly, their distribution in the different Italian Regions was prevalent in North Italy where the incidence of COVID-19 related pneumonitis was higher [27]. It cannot be excluded that also epigenetic markers (including different methylation patterns of gene expression influenced by different dietary habits or noncoding RNAs) may have a role in this phenomenon.

We believe that the role of pollution and epi- and genetic factors should be further investigated and future interventions should be taken to prevent and/or reduce the negative impact of pulmonary-tropism pandemics.

\section{CONFLICTS OF INTEREST}

The authors declare they have no conflicts of interest.

\section{AUTHORS' CONTRIBUTION}

AO contributed in planning, discussing and writing the manuscript. GN, MC, FC, MT, M. Santorsola, M. Scrima, MB and GB contributed in discussing, revising and formatting the manuscript. All authors have read and agreed to the published version of the manuscript.

\section{REFERENCES}

[1] Dettori M, Deiana G, Balletto G, Borruso G, Murgante B, Arghittu A, et al. Air pollutants and risk of death due to COVID-19 in Italy. Environ Res 2021;192;110459.

[2] Alicandro G, Remuzzi G, La Vecchia C. COVID-19 pandemic and total mortality in the first six months of 2020 in Italy. Med Lav 2020;111;351-3.

[3] Buonanno P, Galletta S, Puca M. Estimating the severity of COVID-19: evidence from the Italian epicenter. PLoS One 2020;15;e0239569.

[4] Rizzo M, Foresti L, Montano N. Comparison of reported deaths from COVID-19 and increase in total mortality in Italy. JAMA Intern Med 2020;180;1250-2.

[5] Giorda CB, Manicardi V, Diago Cabezudo J. The impact of diabetes mellitus on healthcare costs in Italy. Expert Rev Pharmacoecon Outcomes Res 2011;11;709-19. 
[6] Grimaccia F, Kanavos P. Cost, outcomes, treatment pathways and challenges for diabetes care in Italy. Global Health 2014;10;58.

[7] Stabile E, Izzo R, Rozza F, Losi MA, De Luca N, Trimarco B. Hypertension survey in Italy: novel findings from the campania salute network. High Blood Press Cardiovasc Prev 2017;24;363-70.

[8] Volpe M, Battistoni A, Gallo G, Rubattu S, Tocci G; Writing Committee; Scientific Societies. Executive summary of the 2018 joint consensus document on cardiovascular disease prevention in Italy. High Blood Press Cardiovasc Prev 2018;25;327-41.

[9] Copat C, Cristaldi A, Fiore M, Grasso A, Zuccarello P, Signorelli SS, et al. The role of air pollution (PM and $\mathrm{NO}_{2}$ ) in COVID-19 spread and lethality: a systematic review. Environ Res 2020; $191 ; 110129$.

[10] Trinh TT, Trinh TT, Le TT, Nguyen TDH, Tu BM. Temperature inversion and air pollution relationship, and its effects on human health in Hanoi City, Vietnam. Environ Geochem Health 2019;41;929-37.

[11] Zhu W, Xu X, Zheng J, Yan P, Wang Y, Cai W. The characteristics of abnormal wintertime pollution events in the Jing-Jin-Ji region and its relationships with meteorological factors. Sci Total Environ 2018;626;887-98.

[12] Yamano M, Goto S, Miyakoshi A, Hamamoto H, Lubis RF, Monyrath V, et al. Reconstruction of the thermal environment evolution in urban areas from underground temperature distribution. Sci Total Environ 2009;407;3120-8.

[13] Su W, Wu X, Geng X, Zhao X, Liu Q, Liu T. The short-term effects of air pollutants on influenza-like illness in Jinan, China. BMC Public Health 2019;19;1319.

[14] HEI Collaborative Working Group on Air Pollution, Poverty, and Health in Ho Chi Minh City; Le TG, Ngo L, Mehta S, Do VD, Thach TQ, et al. Effects of short-term exposure to air pollution on hospital admissions of young children for acute lower respiratory infections in Ho Chi Minh City, Vietnam. Res Rep Health Eff Inst 2012;5-72.

[15] Alonso C, Raynor PC, Davies PR, Torremorell M. Concentration, size distribution, and infectivity of airborne particles carrying swine viruses. PLoS One 2015;10;e0135675.

[16] Alonso C, Raynor PC, Goyal S, Olson BA, Alba A, Davies PR, et al. Assessment of air sampling methods and size distribution

\section{Alessandro Ottaiano ${ }^{1, *}$, Mariachiara Santorsola ${ }^{1}$, Mario Tamburini ${ }^{2}$, Federica Corrado ${ }^{3}$, Marianna Scrima ${ }^{4}$, Marco Bocchetti ${ }^{4,5},(\mathbb{D})$, Gerardo Botti ${ }^{2}$, Guglielmo Nasti ${ }^{1}$, Michele Caraglia ${ }^{4,5}$}

${ }^{1} S S D$-Innovative Therapies for Abdominal Metastases, Istituto Nazionale Tumori di Napoli, IRCCS “G. Pascale”, via M. Semmola, Naples 80131, Italy ${ }^{2}$ Scientific Directorate, Istituto Nazionale Tumori di Napoli, IRCCS "G. Pascale", via M. Semmola, Naples 80131, Italy ${ }^{3}$ Experimental Zooprophylactic Institute of Southern Italy, Naples 80055 , Italy

${ }^{4}$ Laboratory of Precision and Molecular Oncology \& COVID19 Lab, Biogem Scarl, Ariano Irpino 83031, Italy

${ }^{5}$ Department of Precision Medicine, University of Campania "L. Vanvitelli", Via L. De Crecchio, 7, Naples 80138, Italy

"Corresponding author. Email: a.ottaiano@istitutotumori.na.it of virus-laden aerosols in outbreaks in swine and poultry farms. J Vet Diagn Invest 2017;29;298-304.

[17] Piehl S, Mitterwallner V, Atwood EC, Bochow M, Laforsch C. Abundance and distribution of large microplastics (1-5mm) within beach sediments at the Po River Delta, northeast Italy. Mar Pollut Bull 2019;149;110515.

[18] Lai CC, Shih TP, Ko WC, Tang HJ, Hsueh PR. Severe acute respiratory syndrome coronavirus 2 (SARS-CoV-2) and coronavirus disease-2019 (COVID-19): the epidemic and the challenges. Int J Antimicrob Agents 2020;55;105924.

[19] Mirabito Colafella KM, Danser AHJ. Recent advances in angiotensin research. Hypertension 2017;69;994-9.

[20] Nishimura H. Renin-angiotensin system in vertebrates: phylogenetic view of structure and function. Anat Sci Int 2017;92;215-47.

[21] Satou R, Penrose H, Navar LG. Inflammation as a regulator of the renin-angiotensin system and blood pressure. Curr Hypertens Rep 2018;20;100.

[22] Yeung YT, Aziz F, Guerrero-Castilla A, Arguelles S. Signaling pathways in inflammation and anti-inflammatory therapies. Curr Pharm Des 2018;24;1449-84.

[23] Matsuzawa-Ishimoto Y, Hwang S, Cadwell K. Autophagy and inflammation. Annu Rev Immunol 2018;36;73-101.

[24] Moro-García MA, Mayo JC, Sainz RM, Alonso-Arias R. Influence of inflammation in the process of $\mathrm{T}$ lymphocyte differentiation: proliferative, metabolic, and oxidative changes. Front Immunol 2018;9;339.

[25] Correale P, Saladino RE, Giannarelli D, Sergi A, Mazzei MA, Bianco G, et al. HLA expression correlates to the risk of immune checkpoint inhibitor-induced pneumonitis. Cells 2020; $9 ; 1964$.

[26] Correale P, Saladino RE, Giannarelli D, Giannicola R, Agostino $\mathrm{R}$, Staropoli N, et al. Distinctive germline expression of class I human leukocyte antigen (HLA) alleles and DRB1 heterozygosis predict the outcome of patients with non-small cell lung cancer receiving PD-1/PD-L1 immune checkpoint blockade. J Immunother Cancer 2020;8;e000733.

[27] Correale P, Mutti L, Pentimalli F, Baglio G, Saladino RE, Sileri P, et al. HLA-B*44 and C*01 prevalence correlates with Covid19 spreading across Italy. Int J Mol Sci 2020;21;5205. 